\title{
Commentary: From Locke to Merton to lung allocation: Unintended consequences
}

\author{
Ross M. Bremner, MD, PhD
}

\begin{abstract}
The Law of Unintended Consequences: an intervention in a complex system tends to create unanticipated and often undesirable outcomes.
\end{abstract}

-Wikipedia

Allocation of the limited supply of donor organs has always been a great challenge in transplantation. Organ procurement agencies are responsible for the allocation of lungs according to the Final Rule ${ }^{1}$ passed in 1998 and enacted in 2000. The goal of this rule is to allocate organs equitably across the country. Before 2005, patients accrued time on a waiting list and then were offered organs according to the proximity of their "region" to the donor hospital. The change to the lung allocation scoring system in 2005 greatly improved upon the previous time accrual method and has resulted in many improvements, including far fewer patients dying on the wait list. However, organs were still allocated according to regions (areas assigned to the local organ procurement organizations- -58 across the county). More recently, as a result of a lawsuit (and the urgent efforts of the United Network for Organ Sharing Thoracic Committee, over the Thanksgiving holiday, no less), the process of organ allocation with respect to regions was changed in 2017 to encompass a region within a 250 nautical-mile radius from the donor hospital, with a secondary offer to a region within a 500-mile radius.

From Norton Thoracic Institute, St Joseph's Hospital and Medical Center, Phoenix, Ariz.

Disclosures: The author reported no conflicts of interest.

The Journal policy requires editors and reviewers to disclose conflicts of interest and to decline handling or reviewing manuscripts for which they may have a conflict of interest. The editors and reviewers of this article have no conflicts of interest.

Received for publication Oct 9, 2020; revisions received Oct 9, 2020; accepted for publication Oct 9, 2020; available ahead of print Oct 17, 2020.

Address for reprints: Ross M. Bremner, MD, PhD, Norton Thoracic Institute, St Joseph's Hospital and Medical Center, 500 W Thomas Rd, Suite 500, Phoenix, AZ 85013 (E-mail: Ross.Bremner@dignityhealth.org).

J Thorac Cardiovasc Surg 2022;163:348-9

$0022-5223 / \$ 36.00$

Copyright (c) 2020 by The American Association for Thoracic Surgery

https://doi.org/10.1016/j.jtcvs.2020.10.037

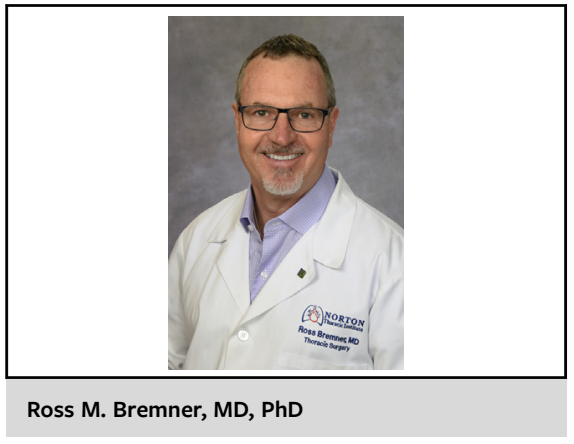

CENTRAL MESSAGE

The 250-mile geographic alloca-

tion rule may have unintended

consequences.

This is beautifully described by Alexandra Glazier, ${ }^{2}$ and I encourage you to read her article. The goal of this change was to more equitably distribute organs from a geographic standpoint.

The effect of the rule has not been identical on all programs, as the authors of this manuscript point out. ${ }^{3}$ Haywood and colleagues ${ }^{3}$ have shown a fairly profound effect on their small- to medium-sized program, especially with an increase in the distance now traveled to get a donor organ, an increase in retrieval costs, and unfortunately, an increase in their wait-list mortality. Clearly, these are unintended consequences of this new geographic rule that are contrary to the goals of the Final Rule. The Discussion of their findings is important, especially as they raise the question about access to transplantation for those with lower socioeconomic status.

However, their experience-and the experience of others-has not gone unnoticed. The Organ Procurement and Transplant Network recognizes that organ allocation is challenging and that our current system is not perfect. They are again working hard to improve these allocation systems. Currently, the Organ Procurement and Transplant Network is working on a new allocation system called continuous distribution. ${ }^{4}$ This new scoring system will take into account (1) medical urgency, (2) post-transplant survival, (3) candidate biology, (4) patient access, and (5) placement efficiency. Complex algorithms will be used, and theoretical modeling and analysis will be performed to "help identify any potential unintended consequences." As a surgeon who has been in the lung transplant world since before the turn of the century (ouch), I have experienced the continued progress that has been made with 
respect to lung allocation. This is hard work and I laud all those involved in improving our allocation systems. I suspect I will witness many further improvements before the end of my career.

\section{References}

1. U.S. Department of Health and Human Services. Organ procurement and transplantation network; final rule. Fed Regist 42 CFR part 121. 1999;56649-566616.
2. Glazier A. The lung lawsuit: a case study in organ allocation policy and administrative law. J Health Biomed L. 2018;XIV:139-48.

3. Haywood N, Mehaffey JH, Kilbourne S, Mannem H, Weder M, Lau C, et al. Influence of broader geographic allograft sharing on outcomes and cost in smaller lung transplant centers. J Thorac Cardiovasc Surg. 2022;163: 339-45.

4. U.S. Department of Health and Human Services. Organ procurement and transplantation network; continuous distribution. Available at: https://optn. Transplant.Hrsa.Gov/governance/policy-initiatives/continuous-distribution/. Accessed October 8, 2020
See Article page 339.

\section{Commentary: All politics are local. The impact of the new organ allocation system on a lung transplant center}

\section{David P. Mason, MD}

Haywood and colleagues ${ }^{1}$ at the University of Virginia lung transplant program describe in their manuscript "Impact of Broader Geographic Sharing on Outcomes and Cost in Smaller Lung Transplant Centers" the effect of national changes that were made in lung distribution and implemented on November 24, 2017. Before this time, lungs for potential adult recipients were allocated according to donation service area (DSA), with prioritization of allocation to patients in the local DSA according to their lung allocation score (LAS). The DSA system of distribution was felt to be unfair because lungs were being offered to lesssick patients in a local DSA whereas sicker patients, even in close proximity but in another DSA, were passed over. Theoretically, this system could be contributing to increased waitlist deaths. Hence, the DSA allocation system was replaced by a system whereby lungs were first allocated by LAS to adult recipients within a 250 mile radius around the donor hospital.

\footnotetext{
From the Baylor University Medical Center, Dallas, Tex.

Disclosures: The author reported no conflicts of interest.

The Journal policy requires editors and reviewers to disclose conflicts of interest and to decline handling or reviewing manuscripts for which they may have a conflict of interest. The editors and reviewers of this article have no conflicts of interest.

Received for publication Oct 8, 2020; revisions received Oct 8, 2020; accepted for publication Oct 9, 2020; available ahead of print Oct 17, 2020.

Address for reprints: David P. Mason, MD, Baylor University Medical Center, 3410

Worth St, Suite 545, Dallas, TX 75246 (E-mail: David.mason@bswhealth.org).

J Thorac Cardiovasc Surg 2022;163:349-50

$0022-5223 / \$ 36.00$

Copyright (c) 2020 by The American Association for Thoracic Surgery

https://doi.org/10.1016/j.jtcvs.2020.10.029
}

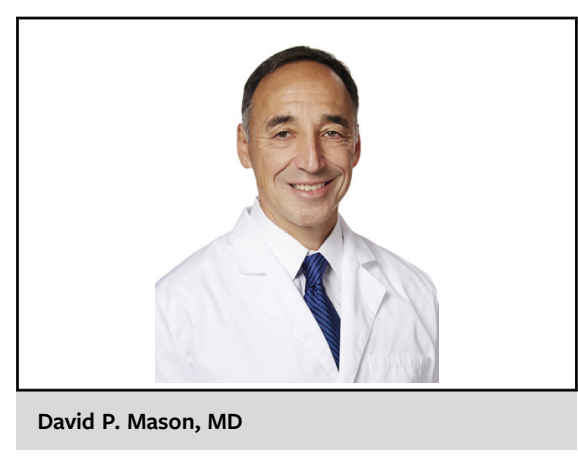

CENTRAL MESSAGE

Change from a donor service area system of lung distribution to one based on proximity to the donor hospital impacts individual transplant centers in unpredictable ways.

When considering this new system, all transplant centers were asking themselves the exact questions that Haywood and his colleagues attempt to answer in this manuscript. How will these nationally implemented changes impact my program on a local level? More specific questions included the following: (1) Will the geographic location of our program disadvantage us? (2) Will we need to travel further to obtain lungs? (3) Will these changes lead to more deaths on our waitlist? (4) Will it cost us more money to transplant?

The authors answered many of these questions at their own center, and some of the answers that are published here are concerning. The number of transplants that they performed in an equivalent time frame before and after implementation of the new system did increase. Travel distance, travel cost, and total procurement costs increased. Waitlist mortality increased. Of greatest concern, the 